\title{
Hydrocarbon resource evaluation using combined petrophysical analysis and seismically derived reservoir characterization, offshore Niger Delta
}

\author{
Kehinde David Oyeyemi $^{1} \cdot$ Mary Taiwo Olowokere $^{2} \cdot$ Ahzegbobor Philips Aizebeokhai $^{1}$
}

Received: 10 November 2016/Accepted: 23 September 2017/Published online: 3 October 2017

(C) The Author(s) 2017. This article is an open access publication

\begin{abstract}
Subsurface characterization and hydrocarbon resource evaluation were conducted using integrated well logs analysis and three-dimensional (3D) seismic-based reservoir characterization in an offshore field, western Niger Delta basin. Reservoir sands R1-R4 were delineated, mapped and quantitatively evaluated for petrophysical characteristics such as net-to-gross, volume of shale, water saturation, bulk water volume, porosity, permeability, fluid types and fluid contacts (GOC and OWC). The volume attributes aimed at extracting features associated with hydrocarbon presence detection, net pay evaluation and porosity estimation for optima reservoir characterization. Neural network (NN)-derived chimney properties prediction attribute was used to evaluate the integrity of the delineated structural traps. Common contour binning was employed for hydrocarbon prospect evaluation, while the seismic coloured inversion was also applied for net pay evaluation. The petrophysical properties estimations for the delineated reservoir sand units have the porosity range from 21.3 to $30.62 \%$, hydrocarbon saturation $80.70-96.90$ percentage. Estimated resistivity $R_{\mathrm{t}}$, porosity and permeability values for the delineated reservoirs favour the presence of considerable amount of hydrocarbon (oil and gas) within the reservoirs. Amplitude anomalies were equally used to delineate bright spots and flat spots; good quality reservoirs in term of their
\end{abstract}

Kehinde David Oyeyemi

kdoyeyemi@yahoo.com;

kehinde.oyeyemi@covenantuniversity.edu.ng

1 Applied Geophysics Unit, College of Science and Technology, Covenant University, Ota, Nigeria

2 Department of Geology, Obafemi Awolowo University, Ile-Ife, Nigeria porosity models, and fluid content and contacts (GOC and OWC) were identified in the area through common contour binning, seismic colour inversion and supervised NN classification.

Keywords Petrophysics - Hydrocarbon prediction . Seismic attributes - Amplitude anomaly $\cdot$ Neural network

\section{Introduction}

The Niger Delta ranked ninth among the world's hydrocarbon provinces with proven recoverable reserves approximately 37,062 millions of barrels (MMbbl) of oil (OPEC 2016) and 5.1 trillion cubic metre of gas resources (BP 2014). This petroliferous basin has more promising reserves yet to be discovered as exploration proceeds into the deeper waters. It has therefore become necessary to apply new exploration and production technologies to harness these hydrocarbon resources. Seismic chimney cube, common contour binning (CCB) and seismic coloured inversion (SCI) are newly introduced approaches for optimal reservoir characterization.

Seismic attributes are qualitative and/or quantitative properties derived from seismic data in order to better understand the physical properties of sedimentary strata (porosity, permeability, bed thickness, etc.). Seismic attributes such as chimneys, common contour binning (CCB) and seismic coloured inversion are examples of qualitative usage of seismic attributes. The specially designed multilayer perceptron (MLP) neural network-modelled seismic chimneys are usually associated with chaotic reflections on seismic sections with low energy and low trace-to-trace similarity associated with the propagation of fluids through fissures and fractures in strata. Seismically derived chimneys seek to formulate a critical relationship between 
chimney characteristics such as occurrence, type and extent with several geologic features (e.g. mud diapirism, active gas seepage and migration pathways) within the hydrocarbon field.

Ever since the first published articles on chimneys technology (Meldahl et al. 1999; Heggland et al. 1999), numerous successful case histories of its application in evaluation of vertical hydrocarbon migration pathways, bright spots, salt diapers, sand bodies, channels, fault sealing capacity and prospect ranking have been reported (Meldahl et al. 2001; Aminzade and Connolly 2002; Connolly et al. 2002; Ligtenberg and Thomsen 2003; Tingdahl 2003). Delineation and mapping of hydrocarbon migration pathways using gas chimneys analyses can show clearly how reservoirs are being charged (Ligtenberg 2005). The results of seismic chimney analyses could also be used to refine $2 \mathrm{D}$ or $3 \mathrm{D}$ basin models for hydrocarbon exploration with a view to thoroughly understand and characterize the available petroleum system, and prioritize exploration plays (Connolly et al. 2013).

Common contour binning (CCB) technique was introduced to proffer solution to the challenges of identifying fluid contacts on seismic profiles that has no significant fluid responses. This method uses the concept of $3 \mathrm{D}$ waveform stacking and enhances the amplitude variances resulting in fluid-type change with a view to identify the various fluid contacts that have no significant seismic response. CCB employs the amplitude stacking of the $3 \mathrm{D}$ seismic post-stack data to enhance and detect subtle anomalies that are related to hydrocarbon accumulation. It expedites the identifications of fluid contacts such as gaswater (GW), gas-oil (GO) and oil-water (OW), which are essential parameters to estimate the original oil in place. The conditions of these delineated contacts affect the optimal productivity of the well as water production in relation to oil and gas production determines the life cycle of a well.

In principle, CCB stacking is based on two assumptions. Firstly, the seismic traces that penetrate a hydrocarbon bearing reservoir at the same depth are meant to have identical hydrocarbon columns. Secondly, all the stacking traces along contour lines enhance possible hydrocarbon effects, whereas the stratigraphic variations and noise are cancelled (dGB 2008). The implication of the second assumption is that when all stacked traces are along the same contour lines, then hydrocarbon effects are expected to be constructively stacked, while both stratigraphic variations and random noise would cancel out. This approach to fluid contacts finder has been employed by Zhao et al. (2013) to delineate the fluid contacts of both anticlinal gas reservoir and structural lithological trap reservoir. The method was also combined with back propagation neural network technique to predict the $\mathrm{OW}$ contacts in Carbonate reservoir, Salawati basin of West Papua (Sutrisno et al. 2013).

Seismic coloured inversion (SCI) method is a trace integration that basically provides a platform where a designed filter can transform the seismic trace into an assumed acoustic impedance equivalent. It has been employed for reservoir characterization by several workers (Ferguson and Margrave 1996; Lancaster and Whitcombe 2000; Veeken and Da Silva 2004; Swissi and Morozov 2009). This technique generates a band-limited inversion of the seismic traces, which then transform them into reflectivity traces through a designed operator in frequency domain. Traditional inversion techniques such as sparsespike and simultaneous inversions are generally known to be time consuming, expensive and sophisticated which require expert users. Seismic coloured inversion is, however, easy to use, cost-effective, robust and model independent, whereby delineated reservoirs are shaper and better defined for qualitative interpretation and further seismic analysis.

\section{Description and geological setting}

The area of study is situated within the offshore depobelts of the Niger Delta in southern Nigeria (Fig. 1), covering an area extent of $102 \mathrm{~km}^{2}$ within the shallow marine environment of the continental shelf. Niger Delta has been identified as a highly prolific hydrocarbon province located in the Gulf of Guinea on the west coast of Africa, bordering the Atlantic Ocean and extends to about longitude $5^{\circ}-8^{\circ} \mathrm{E}$ and latitude $3^{\circ}-6^{\circ} 3^{\circ} \mathrm{N}$. Five extensional depobelts have

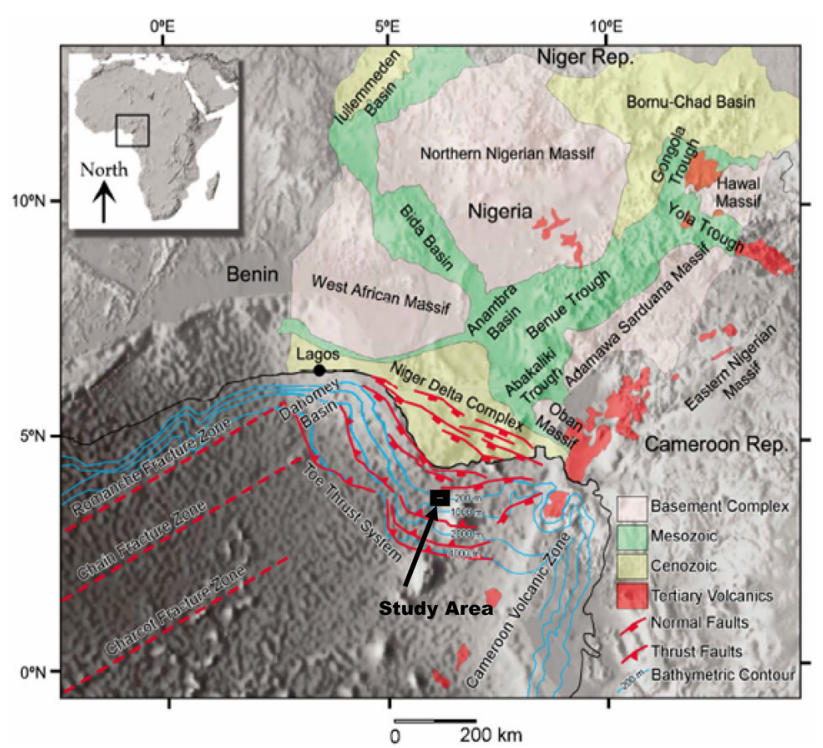

Fig. 1 Map of the Niger Delta showing study location (After Corredor et al. 2005) 
been recognized within the onshore area of Niger Delta, comprising: northern Delta, greater Ughelli, central swamp, coastal swamp and shallow offshore (Damuth 1994); sediments within these depobelts becomes younger seawards. Each depobelt constitutes more or less an independent unit based on structural setting, sedimentation and hydrocarbon generation and accumulation (Evamy et al. 1978).

Three structural belts, namely inner thrust faults, fold belts and the outer thrust belts, were identified within the deep water toe of the Niger delta (Bilotti and Shaw 2005). Both Agbami field and Bonga field were discovered within these fold and thrust belts. The lithostratigraphic characterization of the Niger Delta sediments comprises three stratigraphic units that are of Cretaceous to Holocene; the Akata, Agbada and Benin Formations (Reijers 2011). The depositional environments for these identified stratigraphic units are progradational (Corredor et al. 2005), and the depositional packages comprise of sandstones, silts and shales. The stratigraphic sequence consists of overpressure shales of Akata Formation deposited under fully marine conditions below $3658 \mathrm{~m}$ at the base, overlying by paralic sequence of Agbada Formation (from 914 to $3658 \mathrm{~m}$ ), and the topmost massive continental sands of Benin Formation above $3000 \mathrm{ft}(914 \mathrm{~m})$ to the surface. Niger Delta is typically a wave-and tide-dominated delta characterized by a thick succession of deltaic sediments that have prograded over the passive margin, overlying a ductile substrate of over-pressured shales with thickness range 10-12 km (Doust and Omatsola 1990; Cohen and McClay 1996).

The structural domain of the deepwater Niger Delta is mainly compressional and could be divided into three (3) sub-domains termed the fold and thrust belts, the transitional inter-thrust and the outer fold and thrust sub-domains (Briggs et al. 2006). The regional cross section of the structural and stratigraphic subdivisions of the Niger Delta (Morgan 2004) indicates the variation in structural styles within the basin from extensional to compressional zones. Lithostratigraphic distributions of the different formations are distinctly observed. The topmost Benin Formation (Fig. 2) thins out downslope. Overpressure in the Akata Formation has rendered the Akata structurally weak, and the entire sediment cone has collapsed on intra-Akata detachment faults creating extensional, faulted-diapiric and compressional belt within the region.

The Tertiary Niger Delta formed the petroleum system (Ekweozor and Daukoru 1984; Kulke 1995), with the lower parts of the paralic sequence (Agbada Formation) and uppermost strata of the continuous marine shale (Akata Formation) forming the source rocks. The Agbada Formation formed the hydrocarbon habitat, the sandstone reservoir where oil and gas are trapped in rollover anticlines associated with growth faults. The interbedded shale units within the Agbada Formation serve as the primary seals in Niger Delta. They provide three kinds of seals according to Doust and Omasola (1990); Clay smearing along structural deformations (Faults), interbedded sealing units against which many reservoir sand units are juxtaposed due to faulting, and vertical seals. Major erosional events on the flank of delta (early-middle Miocene) formed clay-filled canyons. These clays serve as the top seals for some important offshore fields in the Niger Delta.

\section{Data analysis and methodology}

\section{Data analysis}

The data used for this research include suites of digital wireline logs (e.g. gamma-ray, resistivity and density logs from three wells, checkshot, and seismic lines. The available 3D seismic reflection data cover $102 \mathrm{~km}^{2}$ area with 637 inlines and 595 crosslines in the interval of 25 . The sampling interval is $4 \mathrm{~ms}$ with sampling intervals per trace of 1251 . The resolution of the seismic section in term of quality was further enhanced using post-processing techniques such as seismic data cropping and data smoothening with structural preserving algorithms. Figure 3 shows the basemap and the location of the drilled wells in the study area. The well correlation to map out various delineated lithologies and reservoir zones was conducted using gamma-ray and resistivity logs. The correlation was done using the stacking patterns such as fining upward, coarsing upward and blocky patterns. Despite the unavailability of the biostratigraphic data, the reservoir correlation was done with respect to a mappable candidate stratigraphic surface (cMFS) across the wells using gamma-ray logs. Four delineated and correlated reservoir sand units were code named R1, R2, R3 and R4 (Fig. 4). The step of 10 with manual horizon tracking tool was used to map out the delineated reservoir horizons across inlines and crosslines on seismic section. Seismic-to-well tie of the reservoir units on both 3D seismic and well logs data was conducted using the derived velocity model from the available checkshot data of well 0555. The time-to-depth conversion technique was used to generate synthetic seismogram which was later employed for seismic coloured inversion.

\section{Evaluation of petrophysical parameters}

Delineation and correlation of the reservoir sand units were carried out with the aid of gamma-ray and resistivity logs signatures. Several mathematical relations and models were equally used alongside pertinent wireline logs to quantitatively determine the petrophysical parameters of the delineated reservoirs such as volume of shale, net-to- 
Fig. 2 Stratigraphic column of the Niger Delta basin (Doust and Omatsola 1990)
SOUTHWEST

NORTHEAST

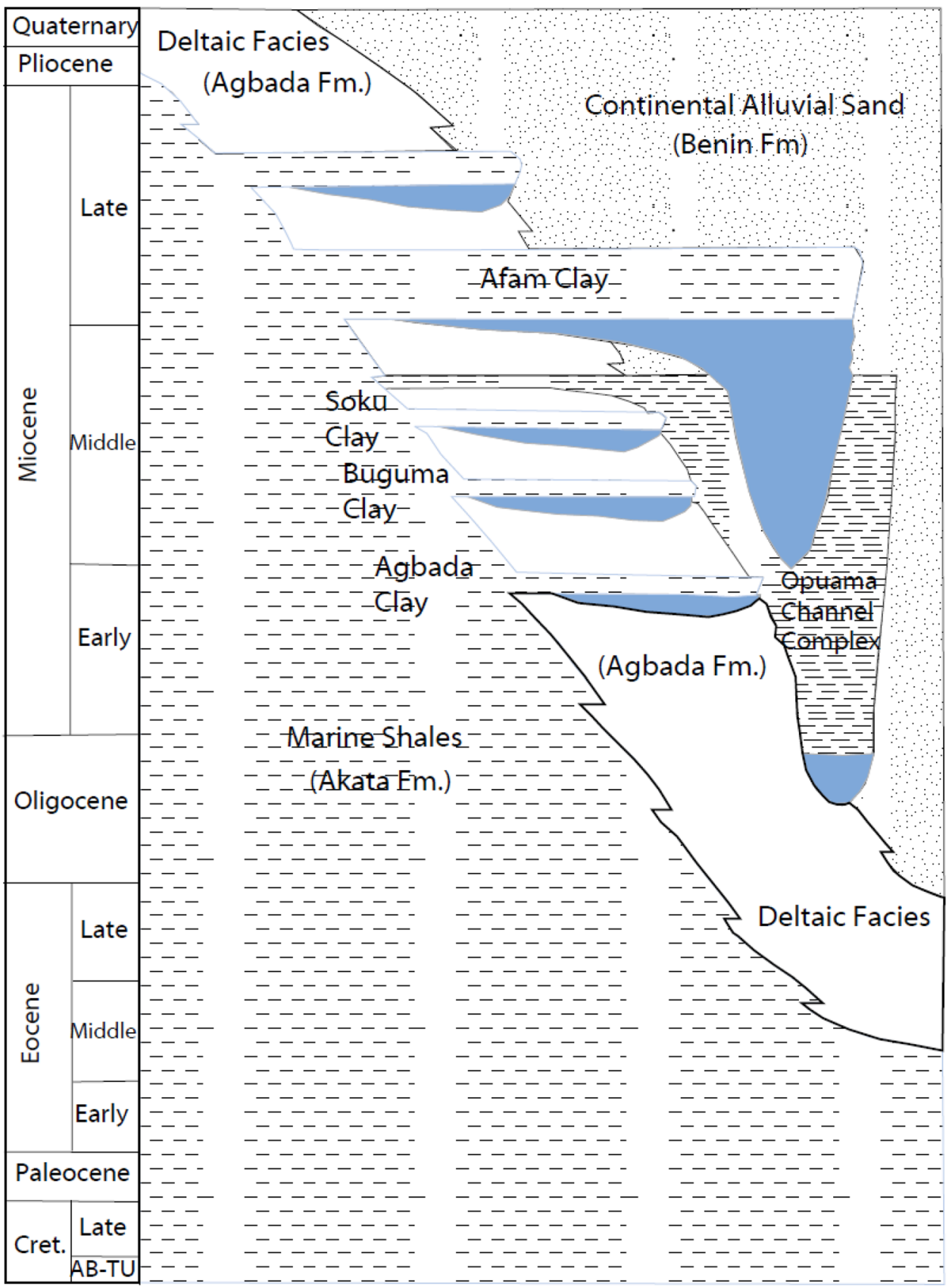

\section{Extent of erosional truncation}

gross, water saturation, hydrocarbon saturation, bulk volume of water, porosity and permeability.

\section{Net-to-gross sand estimation}

Reservoir lithological characterization in terms of sand and shale distributions was done based on shale volume determination using Eqs. (1) and (2) for tertiary unconsolidated rocks after Larinov (1969)and Schlumberger
(1989). The volume of shale was estimated from gammaray $\log$, and well log cut-offs were applied based on shale volume and effective porosity in order to determine net reservoir rock. Net-to-gross (NTG) ratio estimation was carried out with a view to evaluate the sand units within the study area and determine their quality as a potential reservoir. High NTG value connotes a good quality hydrocarbon reservoir (Al-Baldawi 2014). 


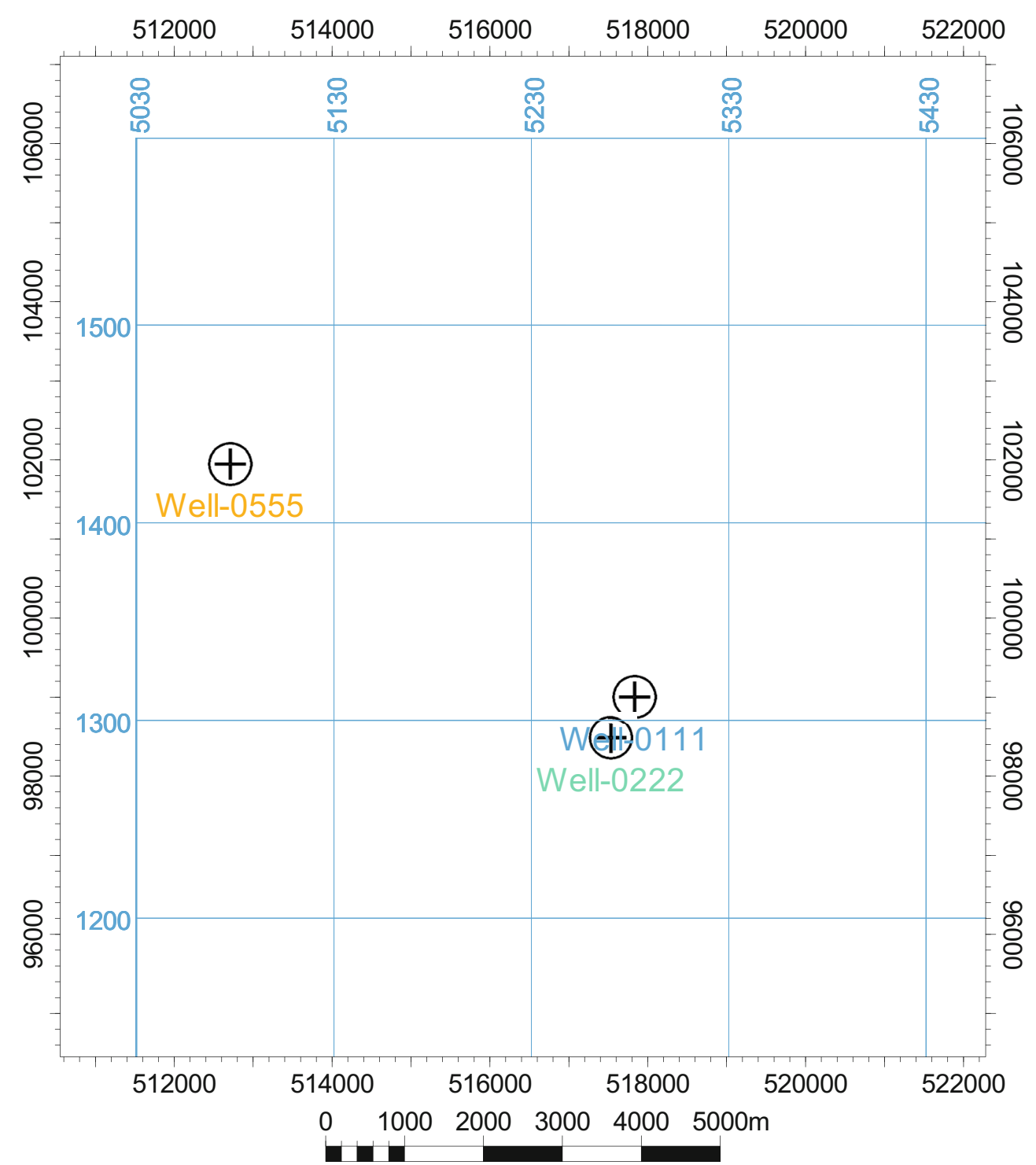

$1: 78125$

\begin{tabular}{|c|c|}
\hline \multicolumn{2}{|l|}{ Map } \\
\hline Country & \begin{tabular}{|c|} 
Scale \\
$1: 78125$
\end{tabular} \\
\hline Block & Contour inc \\
\hline License & $\begin{array}{r}\text { User name } \\
\text { David Oyeyemi }\end{array}$ \\
\hline Model name & \begin{tabular}{|l} 
Date \\
$06 / 01 / 2017$
\end{tabular} \\
\hline Horizon name & Signature \\
\hline
\end{tabular}

Fig. 3 Base map of the study area

$$
\begin{aligned}
I_{\mathrm{GR}} & =\frac{\mathrm{GR}_{\log }-\mathrm{GR}_{\min }}{\mathrm{GR}_{\max }-\mathrm{GR}_{\min }} \\
V_{\mathrm{Sh}} & =0.083\left[2^{\left(3.7 * I_{\mathrm{GR}}\right)}-1.0\right]
\end{aligned}
$$

(1) where $V_{\mathrm{Sh}}$ and $I_{\mathrm{GR}}$ are the shale volume and gamma-ray index, $\mathrm{GR}_{\log }$ is the gamma-ray reading $\log , \mathrm{GR}_{\min }$ and $\mathrm{GR}_{\max }$ are the minimum and maximum reading from gamma-ray log. 


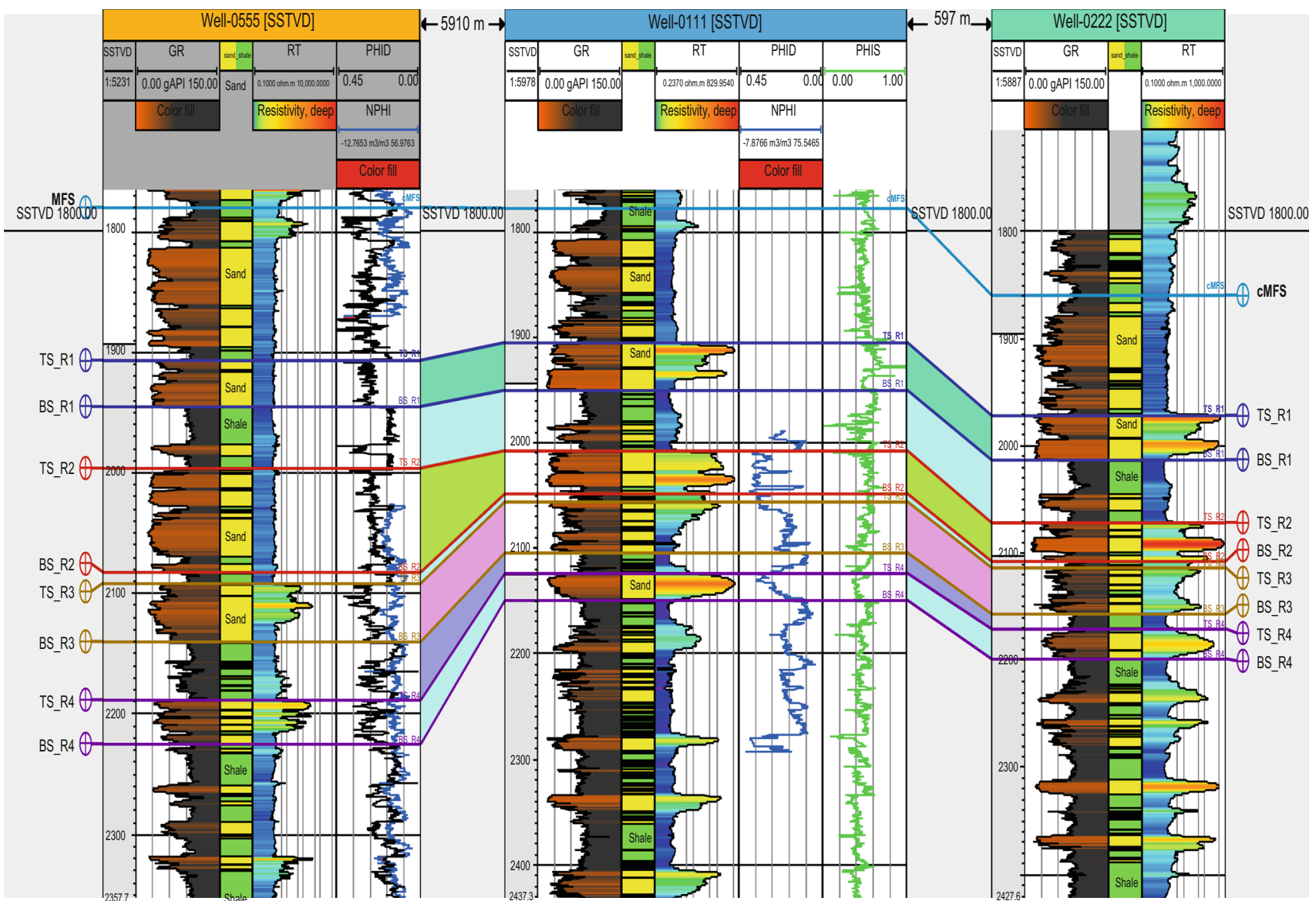

Fig. 4 Well section window showing the reservoir zonation and correlation

\section{Porosity determination}

Porosity signifies the amount of voids or pore spaces in the rock volume, and the quantification of the amount of fluids the rock can hold. Both bulk density (RHOD) and neutron (NPHI) logs were utilized for porosity estimation using Asquith Eqs. (3) and (4) (Asquith and Krygowski 2004) for the hydrocarbon bearing reservoirs in well 0555. Wyllie time average Eq. (5) according to Wyllie et al. (1956) was used to estimate porosity from the sonic log. In a poorly consolidated, unconsolidated and/or uncompacted reservoir sand, a correction factor is necessary. Equation. (6) involving the empirical compaction factor was then applied to effect this correction. Since change in interval transit time $\Delta t$ generally increases with hydrocarbon, sonic porosities $\phi_{\mathrm{S}}$ of all the mapped reservoirs across well 0111 were corrected for fluid effects using Eq. (7). The neutrondensity porosity $\phi_{\mathrm{ND}}$ (well 0555 ), and sonic porosity $\phi_{\mathrm{S}}$ (PHIS) were engaged to calculate the effective porosity (PHIE) $\phi_{\text {eff }}$ for shaly reservoir formations using Asquith and Krygowski (2004) Eq. (8). Fluid types, content and contacts were also identified using density-neutron crossover.
$\phi_{\mathrm{D}}(\mathrm{PHID})=\frac{\rho_{\mathrm{g}}-\rho_{\mathrm{b}}}{\rho_{\mathrm{g}}-\rho_{\mathrm{f}}}$

$\phi_{\mathrm{ND}}=\frac{\phi_{D}+\phi_{N}}{2}$

where $\rho_{\mathrm{g}}, \rho_{\mathrm{f}}$ and $\rho_{\mathrm{b}}$ are the grain density $(2.65 \mathrm{~g} / \mathrm{cc})$, apparent fluid density $(1.01 \mathrm{~g} / \mathrm{cc})$ and the bulk density from the density log, respectively.

$\begin{aligned} \phi_{\mathrm{S}}(\mathrm{PHIS}) & =\frac{\Delta t_{\mathrm{log}}-\Delta t_{\mathrm{ma}}}{\Delta t_{\mathrm{f}}-\Delta t_{\mathrm{ma}}} \\ \phi_{\mathrm{S}}(\mathrm{PHIS}) & =\frac{\Delta t_{\log }-\Delta t_{\mathrm{ma}}}{\Delta t_{\mathrm{f}}-\Delta t_{\mathrm{ma}}} * \frac{1}{C_{\mathrm{P}}}\end{aligned}$

And $C_{\mathrm{P}}=C \frac{\Delta t_{\mathrm{Sh}}}{100}$

$\phi_{\mathrm{S}(\text { corrected })}=0.9 \phi_{\mathrm{S}}$

$\phi_{\mathrm{eff}}=\left(1-V_{\mathrm{Sh}}\right) \varphi, \phi=\phi_{\mathrm{ND}}$ or $\phi_{\mathrm{S}}$

where $\Delta t_{\text {ma }}, \Delta t_{\mathrm{f}}$ and $\Delta t_{\log }$ are the matrix interval transit time $(55.5 \mu s / f t)$, apparent fluid interval transit time (189 $\mu s / f t$ ) and the interval transit time from the sonic log, respectively. $C$ is the shale compaction coefficient ranging from 1.0 to 1.3 depending on the regional geology. $\Delta t_{\text {Sh }}$ is 
the specific acoustic transit time in adjacent shales, whereas $100 \mu s / f t$ is the acoustic transit time in a compacted shales.

\section{Estimation of water and hydrocarbon saturation}

Water saturation as the percentage of the reservoir volume that is made up of water was estimated using Archie Eq. (9)

$S_{\mathrm{w}}=\sqrt{\frac{a * R_{\mathrm{w}}}{R_{\mathrm{t}} * \phi^{m}}}$

where $a$ and $m$ are the tortuosity and cementation exponent taking as 0.81 and 2, respectively, $\phi$ is the porosity ( $\phi_{\mathrm{ND}}$ or $\left.\phi_{\mathrm{S}}\right) . R_{\mathrm{t}}$ is the true resistivity of the formation measured by deep laterolog on the assumption that the formation is greater than $1 \mathrm{~m}$ (about $3 \mathrm{ft}$ ), and the formation invasion is not too deep (Asquith and Krygowski 2004). $R_{0}$ is the resistivity of the reservoir when the entire fluid is water and $R_{\mathrm{w}}$ is the formation water resistivity at the formation temperature, it is determined using Eq. (10) from both the resistivity and porosity $\operatorname{logs}$ within clean water zone.

$R_{\mathrm{w}}=\frac{\phi^{m} R_{0}}{a}$

Consequent hydrocarbon saturation $S_{\mathrm{h}}$ (Schlumberger 1989) denoting the percentage of the pore volume in a formation occupied by hydrocarbon is determined using Eq. (11).

$S_{\mathrm{h}}=\left(100-S_{\mathrm{w}}\right) \%$

\section{Bulk volume of water determination}

Bulk volume of water (BVW) which determines whether the hydrocarbon from the reservoir would be water free or not was estimated using Eq. (12) according to Morris and Briggs (1967).

$\mathrm{BVW}=S_{\mathrm{w}} \times \phi$

\section{Permeability estimation}

Free-fluid Coates model that is applicable to water saturated and/or hydrocarbon-saturated reservoirs was used in this research. The model assumes a good correlation between porosity, pore throat size and pore connectivity. This model has been validated, with the assumptions valid for clastic reservoirs such as those in the Niger Delta basin. Equation (13) used after Coates and Denoo (1981) was derived to ensure zero permeability as porosity and water saturation approach zero and hundred percentage, respectively.

$\left.K^{1 / 2}=\left[100 \phi_{e}^{2}\left(1-S_{\mathrm{wi}}\right) / S_{\mathrm{wi}}\right)\right]$
$S_{\mathrm{wi}}^{2}=\frac{F}{2000}, F=\frac{a}{\phi^{m}}$

where $S_{\mathrm{wi}}$ is irreducible water saturation, $F$ is the formation factor and all other symbols have their usual meanings.

\section{Dip-steering attribute}

The dip-steering attribute analysis allows the creation of steering cube that contains both local dip and azimuth positions at each sample position. The attribute is quite useful for improved faults and fault zones detection. Its application minimizes the sensitivity of similarity to dipping reflectors with no apparent link to faulting by aligning adjacent trace segments with lag time. A steering cube designed using dip-steered median filter attribute can be used to effectively perform a structurally oriented filtering. When a dip-steered similarity attribute is employed, dip-steering cube can be used for enhancing multi-trace attributes simply by extracting attributes input along the reflectors. Other applications of dipsteering attributes include the estimation of some unique attributes such as dip and azimuth, 3D curvature and dip variance. 3D image of the principle of dip-steering attributes estimation is presented in Fig. 5; the arrows are pointing in various steering directions. Two scenarios of the dip-steering computation as applicable to the 3D seismic data are shown (Fig. 6). The first case depicts the original data where trace segments are aligned horizontally whereas the second case shows the effects of the applied full steering attribute, the location and azimuth of the traces are being updated at each trace location. Figure 7 presents the general workflow used in this study to dip steer the available 3D seismic data.

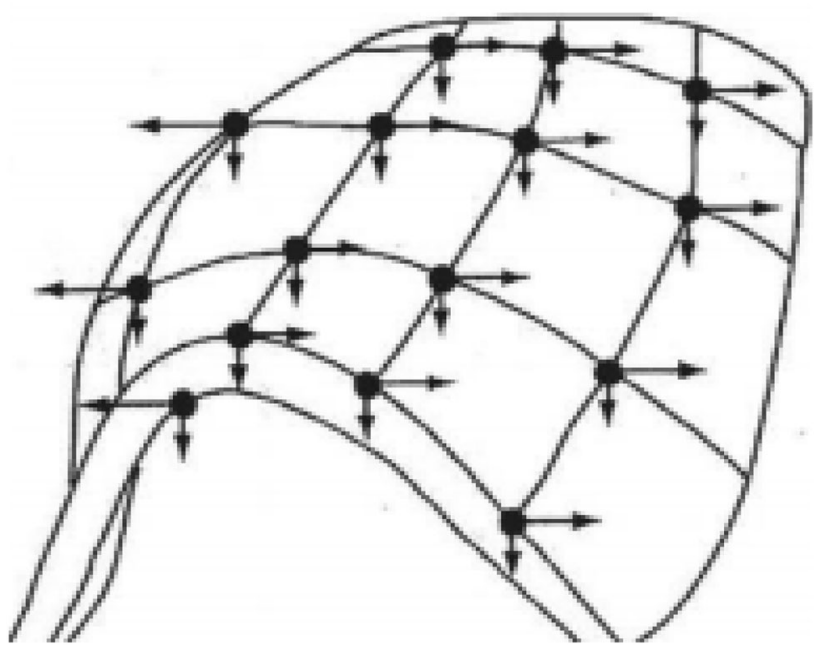

Fig. 5 Dip-steering attribute

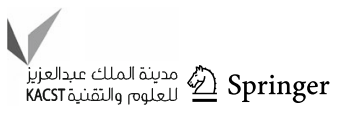




\section{Seismic chimneys analyses}

Gas chimney is detected in seismic data as vertically aligned chaotic zones with low amplitude and reflectivity. The procedures adopted in this study for creating the supervised multi-layer perceptron neural network-modelled gas chimneys cube as shown in Fig. 8 involve: (1) calculating and extracting a set of single-trace attributes and directional attributes (such as energy, frequency, continuity, dip variance, similarity and azimuth variance) that distinguish between chimneys and non-chimneys; (2) designing and training a multi-layer perceptron (MLP) neural network with extracted attributes at interpreted chimneys and non-chimneys locations; (3) generating a chimney cube volume using the multi-attributes transformation of the dip-steered 3D seismic volume highlighting the vertical disturbances as the output of the trained neural network; and (4) visualizing and interpreting the chimney volume. A key step in generating chimney cube is the time window over which the attributes are extracted both below and above the points of investigation. In this research, time gate windows of $[-40,40] \mathrm{ms}$ length were used in order to help differentiate the chimneys from the background noise. Also, the use of dip-steered data for gas chimneys creation enhanced the discriminatory power of the all the extracted attributes where local dip information is utilized.

Ninety picksets each for the two major categories of Chimney_Yes and Chimney_No picksets were manually picked and used to tag locations that appear as chimneys (Chaotic) and smooth, respectively, across the entire 3D seismic data. These picksets were saved and later trained by pattern recognition algorithm using supervised method of multi-layer perceptron neural network to map the entire 3D seismic dataset. Thirty percentage $(30 \%)$ confidence level was selected to train the selected picksets which later become the training vectors across the volume data. The training vectors were passed through the multi-layer perceptron-type neural network, and the error was used to update the weights. Also the test vectors were passed through the multi-layer perceptron-type neural network, while the error was used to check the training performance and avoid overfitting. The entire training process was stopped when the error on the test set was minimal, and this occurred when the normalized RMS curve with respect to the percentage miscalculation curve became flat. The output nodes of the neural network are Chimney_Yes and Chimney_No with values approximately between 0 and 1 representing the chimney probability. Choosing a threshold value, this method creates binary values indicating presence or absence of chimneys.

\section{Common contour binning}

CCB was applied on already structurally mapped polygons on both R1 and R2 horizons with intentions of identifying subtle hydrocarbon-related anomalies and delineating contacts (GWC, GOC and OWC). Expected outcome of CCB analysis usually include 2D section with stacked traces and a crossplot of stacked amplitudes against bin depth. The designated polygon on $\mathrm{R} 1$ has inline/crossline (5101/1031-5585/1557) of 1251 samples with Z-values (450-700 ms.). However, the mapped structurally polygon for R2 of 5126/1048 to 5582/1562 has 1251 samples and Z-slice values (500-750 ms.); a total of 260483 traces were stacked for CCB of R2 horizon.

\section{Seismic coloured inversion (SCI)}

Seismic coloured inversion is similar to seismic processing in approach whereby the seismic data passed through white spectrum during deconvolution. The entire procedures and workflow (Fig. 9) employed in carrying out SCI are similar
Fig. 6 Cross-sectional schematic illustration of dipsteering computation applied to the seismic data (Tingdahl 2003)
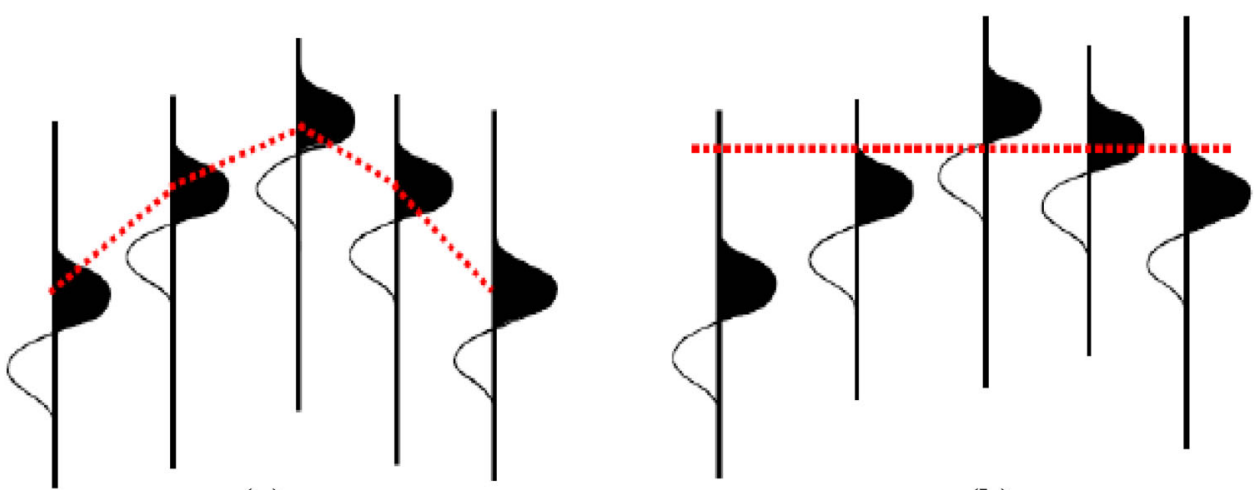

(a) (b)

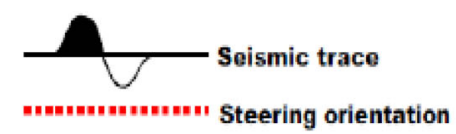


Fig. 7 Dip-steering workflow (After dGB 1995)
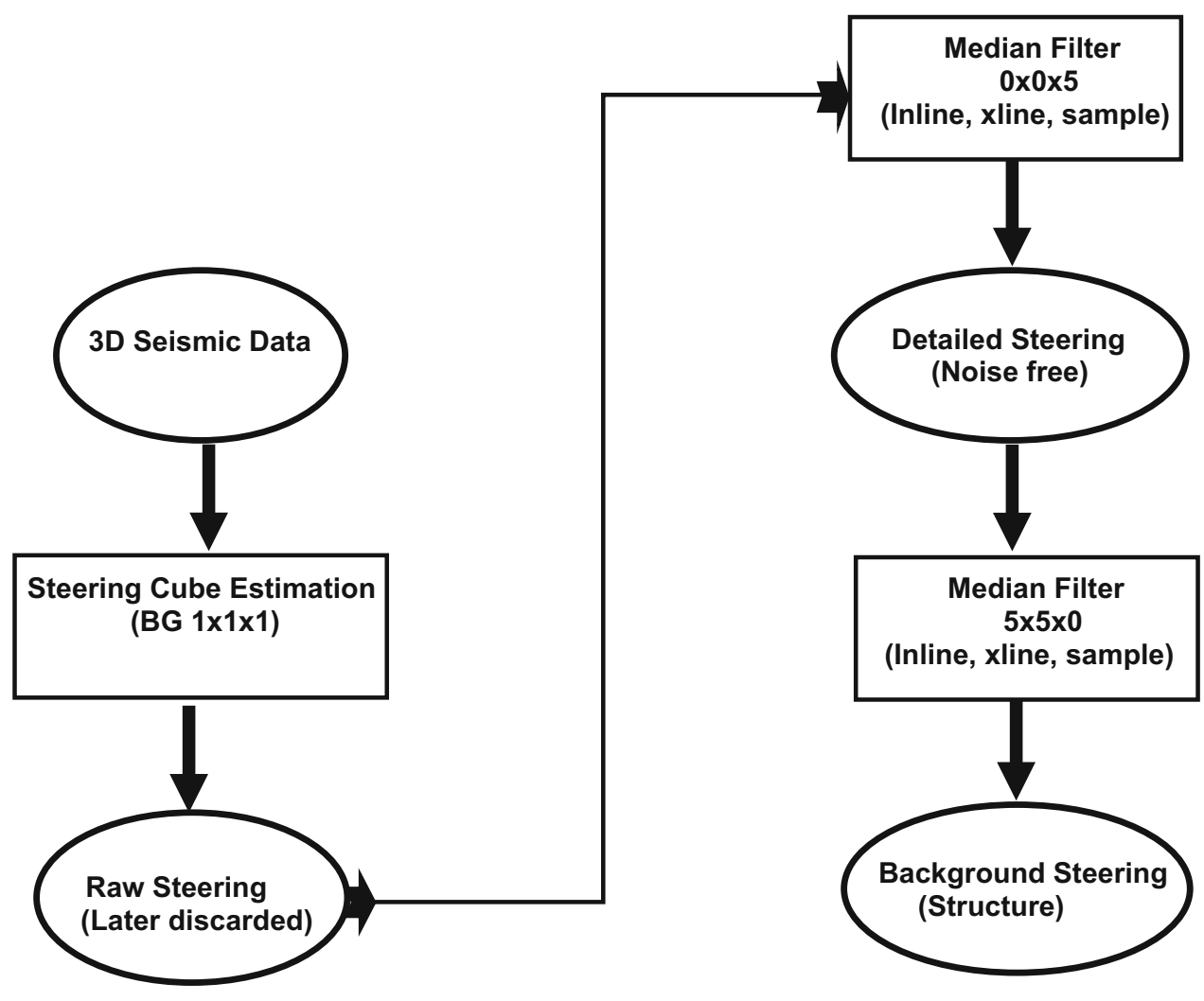

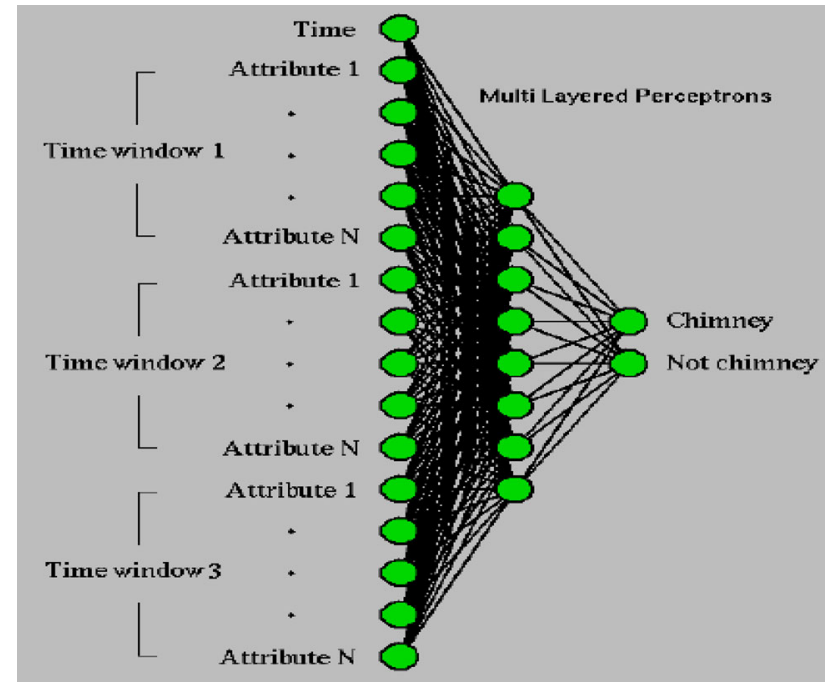

Fig. 8 Input attributes to a multi-layer perceptrons (MLP) neural network to obtain chimney probability

to that of Lancaster and Whitcombe (2000), and Veeken and Da Silva (2004). The 3D seismic dataset and well 0111 sonic and density logs spectra within the inversion window were compared and analysed to design the amplitude spectrum of a specific operator. This process ultimately brought the seismic amplitudes to correspond with those observed in the well logs. The designed operator was then engaged to modify the average seismic trace spectral in

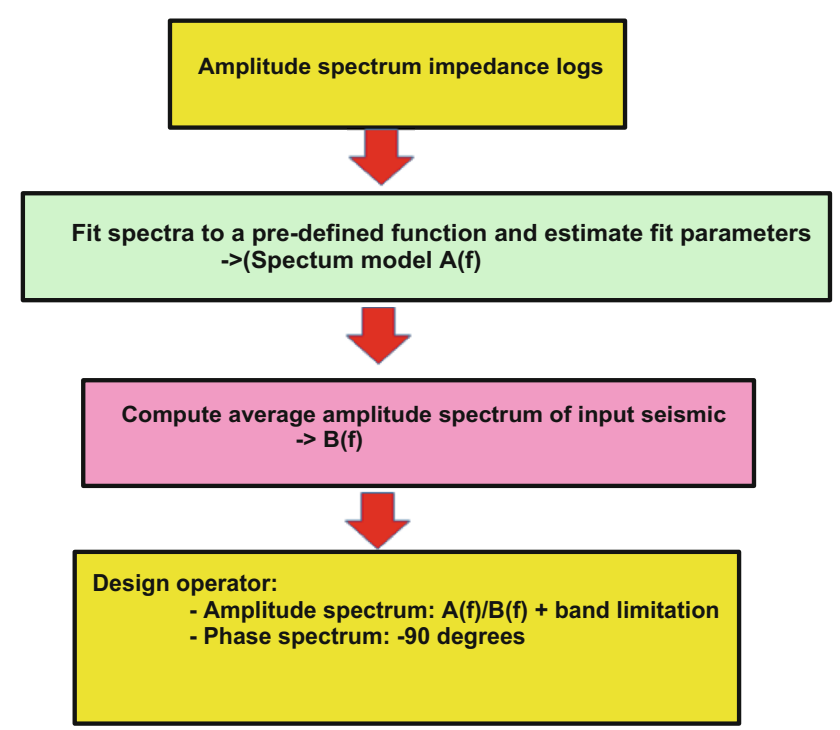

Fig. 9 SCI method workflow (After Veeken and Da Silva, 2004)

order to be as nearly closed to the fitted curve representing the average acoustics impedance spectrum as possible. The phase spectrum of the designed SCI operator was then rotated by $-90^{\circ}$ (Lancaster and Whitcombe 2000); a bandpass filter was applied and the new spectrum was converted to time. 3 and $108 \mathrm{~Hz}$ were the low-cut and high-cut frequency parameters for the designed operator at $-60 \mathrm{~dB}$ amplitude. The designed seismic coloured 
inversion operator, based on the band-limited impedance algorithm in time domain (Ferguson and Margrave 1996), was finally applied to the entire 3D seismic data as a "userdesigned filter" through a predefined convolution procedure. The general assumption of this method of inversion is that the seismic data used is zero-phase and has been compensated for by the phase rotation of the designed operator.

\section{Results and discussion}

\section{Petrophysical evaluation}

The lithologic delineation, reservoirs mapping and correlation across all the well logs were achieved using gammaray (GR) log; major delineated lithofacies in this field are interbedding sand and shale units. The shale units serve as seals to the delineated reservoirs in this field. The quantitative attributes of the mapped reservoir sand units were evaluated for porosity, water saturation, reservoirs net-togross and other petrophysical parameters. These estimated petrophysical characteristics are presented in Tables 1 and 2. Porosity values estimated for all the delineated reservoir sand units in accordance with Lavorsen (1967) fall within the very good range with values $26.3-30.62$ percentage in well $0111 ; 21.30-28.30$ percentage in well 0555 . The values of the water saturation range between 3.10 and 12.02 percentage in well 0111 , and $7.20-19.30$ percentage in well 0555 .

Hydrocarbon saturation values range 87.98-96.90 percentage in well 0111 and $80.70-92.80$ percentage in well 0555; R4 has the highest value of hydrocarbon saturation. The permeability values, denoting the capacity of the reservoir units to transmit fluids, range $2606.90-11,800.0 \mathrm{mD}$ in well $0111,1050.10-6502.31 \mathrm{mD}$ in well 0555 . These observations from the permeability values are strongly connected to low shaliness of the reservoirs. The reservoir sand units have high porosities and permeabilities pointing to the fact that they might have been deposited in a progradational shallow marine shelve depositional environment with lesser degree of grain size sorting. Also, variation in these petrophysical parameters across all the mapped reservoirs could be tied to the differential shale volume intercalating within the reservoir sand units; and the wide differences between the estimated permeability values in both wells are not unconnected to the calculated porosities from sonic and neutron-density logs of well 0111 and well 0555 , respectively. Therefore, good prospectivity of the mapped reservoirs is evident from the estimated petrophysical attributes, and the hydrocarbon accumulation within all the delineated reservoirs is economically viable for commercial exploitation. Computations of petrophysical parameters in this study were not considering the structural uncertainties that are associated with definition of both fluid contacts and fault plane. These may result in inaccurate assessment of reservoir compartmentalization which could cause ambiguity in estimating gross rock volume and hydrocarbon volume (Shepherd 2009). However, all the estimated petrophysical parameters are in line with those reported by other researchers in Niger Delta (Adeoye and Enikanselu 2009; Opara 2010; Mode et al. 2014); they formed the essential parameters to quantitatively determine the stock tank oil initially in place (STOIIP) in the field.

\section{Seismic structural analysis}

Seismic interpretations as presented in Fig. 10 revealed three major down-to-south growth faults terminating against a large faults closure, two intermediate synthetic and antithetic faults dissecting the main body of the field. F7 and F8 constitute the minor antithetic and growth faults, respectively. The entire structural trapping mechanism consists of an anticlinal structure at the centre of the hydrocarbon field tying to the rollover structure crest of the assisted by the major faults. Structural pull-ups structures are also localized in the field. These structural traps are responsible for the hydrocarbon accumulation and entrapment.

\section{Chimney cube}

Chimney processing uses multi-directional attributes combined via a neural network to highlight chimneys in the dataset. Expected chimneys are picked in the data

Table 1 Estimated petrophysical parameters at well 0111

\begin{tabular}{lllllllllllll}
\hline & Depth interval & NTG $(\%)$ & $V_{\mathrm{Sh}}(\%)$ & $R_{\mathrm{t}}(\Omega \mathrm{m})$ & $R_{\mathrm{w}}(\Omega \mathrm{m})$ & $\phi_{\mathrm{S}}(\%)$ & $F$ & $S_{\mathrm{w}}(\%)$ & $\mathrm{BVW}(\%)$ & $S_{\text {wirr }}(\%)$ & $K(\mathrm{mD})$ & $S_{\mathrm{h}}(\%)$ \\
\hline $\mathrm{R} 1$ & $1904.56-1948.81$ & 91.65 & 8.59 & 333.000 & 0.0189 & 26.3 & 13.5 & 3.10 & 0.80 & 8.22 & 4168.80 & 96.90 \\
$\mathrm{R} 2$ & $2007.22-2047.93$ & 91.65 & 7.03 & 242.362 & 0.1337 & 28.5 & 13.5 & 9.59 & 2.73 & 8.22 & 6148.03 & 90.41 \\
$\mathrm{R} 3$ & $2057.66-2101.91$ & 76.77 & 10.20 & 482.148 & 0.2091 & 30.62 & 8.43 & 6.72 & 2.06 & 6.49 & 11821.19 & 93.28 \\
$\mathrm{R} 4$ & $2123.15-2148.81$ & 81.86 & 26.12 & 93.460 & 0.0949 & 27.5 & 11.54 & 12.02 & 3.36 & 7.60 & 2520.06 & 87.98 \\
\hline
\end{tabular}


Table 2 Estimated petrophysical parameters at well 0555

\begin{tabular}{llllrllllllll}
\hline & DEPTH INTERVAL & NTG $(\%)$ & $V_{\mathrm{Sh}}(\%)$ & $R_{\mathrm{t}}(\Omega \mathrm{m})$ & $R_{\mathrm{w}}(\Omega \mathrm{m})$ & $\phi_{\mathrm{ND}}(\%)$ & $F$ & $S_{\mathrm{w}}(\%)$ & $\mathrm{BVW}(\%)$ & $S_{\mathrm{wirr}}(\%)$ & $K(\mathrm{mD})$ & $S_{\mathrm{h}}(\%)$ \\
\hline R1 & $1907.22-1946.49$ & 92.14 & 12.83 & 177.737 & 0.1468 & 27.75 & 10.52 & 10.36 & 2.87 & 7.25 & 5603.96 & 89.64 \\
$\mathrm{R} 2$ & $1996.28-2083.57$ & 89.99 & 8.17 & 181.480 & 0.1344 & 28.30 & 10.15 & 9.63 & 2.72 & 7.12 & 7764.42 & 90.37 \\
$\mathrm{R} 3$ & $2092.86-2137.78$ & 84.45 & 16.47 & 316.325 & 0.0919 & 23.50 & 14.67 & 7.20 & 1.70 & 8.56 & 1694.36 & 92.80 \\
$\mathrm{R} 4$ & $2186.90-2224.52$ & 68.64 & 11.01 & 54.970 & 0.0927 & 21.30 & 17.92 & 19.30 & 4.11 & 9.47 & 1178.48 & 80.70 \\
\hline
\end{tabular}

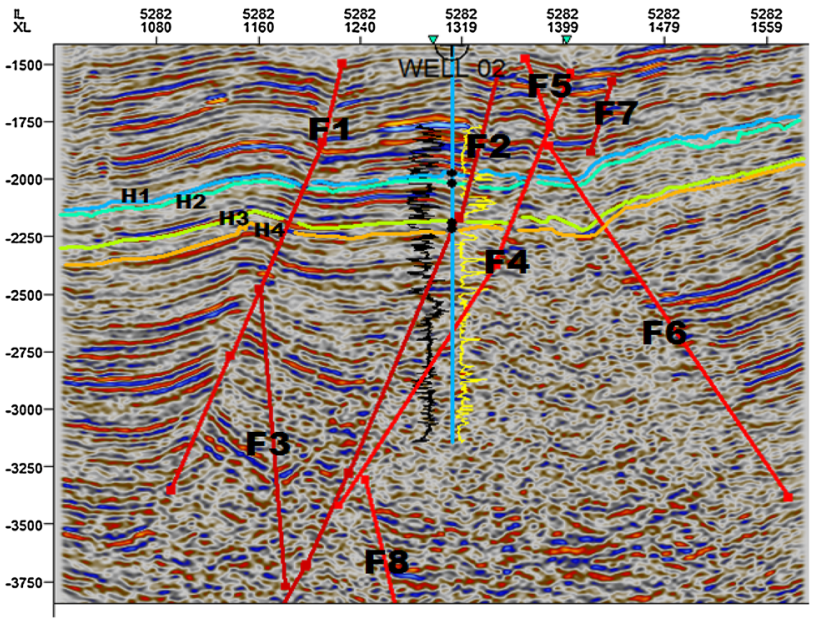

Fig. 10 Seismic structural analysis at inline 5282

and used to train the neural network to find similar features. The entire processes result in the creation of chimney cube. Figure 11 presents the seismic chimneys observed on inline 5282. Chimneys are found throughout the entire 3D seismic dataset pointing to the localization of faults and fluid migration paths. The presence of gas chimney along faults gives an indication that the faults are open or have been open for a time, in which case fluids can migrate through the faults (Heggland 2004).

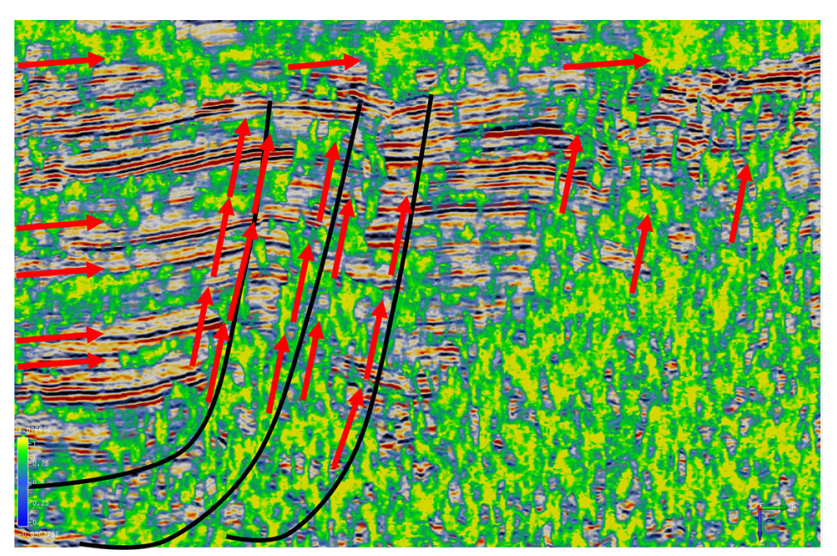

Fig. 11 Seismic chimneys analysis on inline 5282
The fluid migration appears to be vertically upward with larger portion of these fluids settling closer to the surface about 1.5 and $1.7 \mathrm{~s}$ (Fig. 11). This may be an indication that the delineated faults in this field are perhaps leaking, where the trapped hydrocarbon have seeped or migrated upwards as seepages.

\section{Common contour binning}

The results of un-flattened $\mathrm{CCB}$ of seismic amplitude in both mapped reservoir sand units (R1 and R2) are displayed in Figs. 12 and 13. The signal amplitudes for both reservoirs range $0-15,000$ trending predominantly NE-SW (Figs. 12c, 13c). Two gas-oil contacts (GOC) at 620 and 680 Z-slices were mapped out from CCB stacked of R1(Fig. 12a) while one GOC at 540 Z-slice values with two oil-water contacts (OWC) at both 570 and $630 \mathrm{Z}$-slices values, respectively, were delineated from CCB stacked of R2 (Fig. 13a). Pockets of gas are predominant in reservoir R1 (Fig. 14a) with less oil (shown as red), whereas reservoir R2 is rich in oil towards the SW and NW areas (Fig. 14b). The observed oil water contacts in R2 are fairly sharp covering a few feet. The top of the transition zone which is the contact between the oil and water is known to be the base of the clean oil production, while the base of the transition zone is the top of free water zone. The length of this transition zone is observed to be relatively short denoting higher permeability of reservoir R2.

\section{Seismic coloured inversion}

Seismic coloured inversion window displays all the SCI parameters and the residual operator (QC) chart (Fig. 15). The chart shows a well log impedance curve in green and the corresponding smooth average spectrum of the colour inverted random traces in red. It can be observed that bandlimited impedance log curve actually fits within a specific bandwidth specify for the set of random seismic traces. It is expected that amplitude of the residual operator in blue should be zero within the specified bandwidth. The coloured inversion design operator was used to possibly adjust the smooth seismic mean spectrum to curve fit the impedance $\log$ at every frequency such that the log input 
Fig. 12 Reservoir R1 (a) CCB stacked (b) Crossplot of stacked amplitudes vs. bin depth (c) Amplitude directional attributes
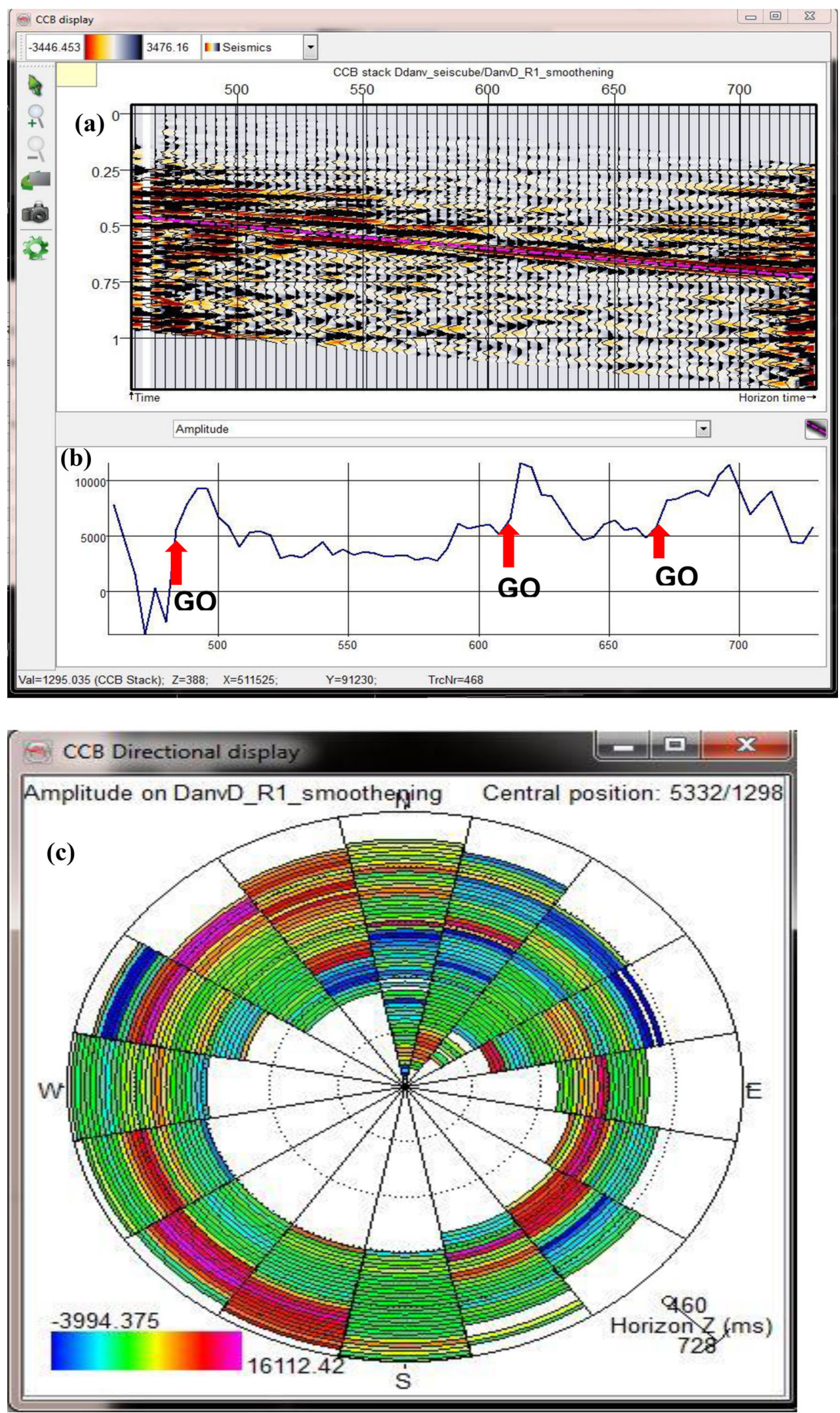
Fig. 13 Reservoir R2 (a) CCB stacked (b) Crossplot of stacked amplitudes vs. bin depth (c) Amplitude directional attributes
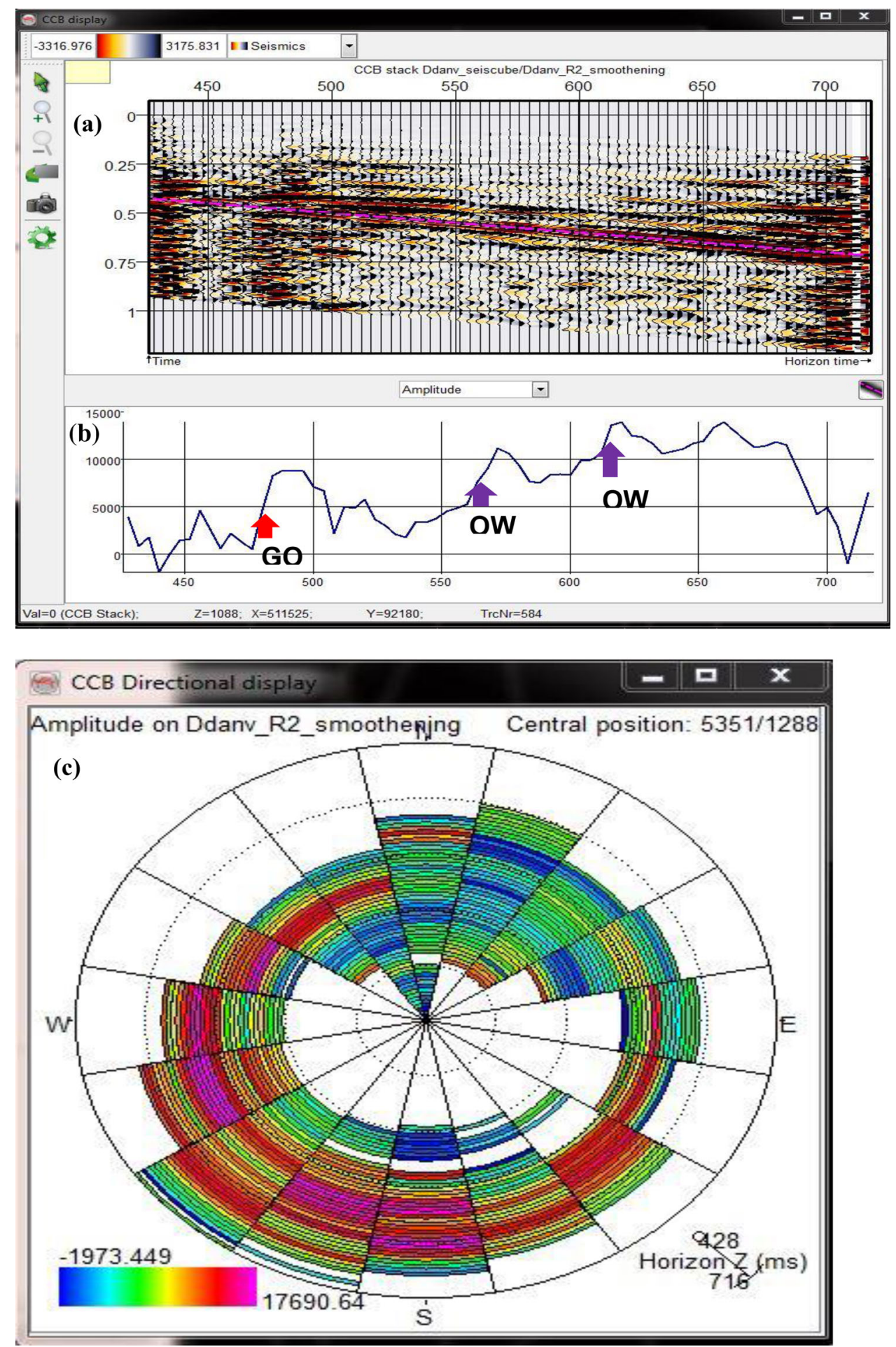

chart would then show the impedance logs in time domain. Reflectors in seismic-inverted section on inline 5364 as presented in Fig. 16 are sharper with improved definition. The intervals of the mapped reservoirs units in the inverted seismic section also appear better defined for qualitative interpretation.

\section{Conclusions}

The following are the conclusions drawn from this study:

I. Analysis of the petrophysical parameters evaluation for the four delineated reservoir sand units within the study area revealed hydrocarbon saturation ranging from 
Fig. 14 Common contour binning (CCB) attributes analysis on reservoir R1 (a) and R2 (b)
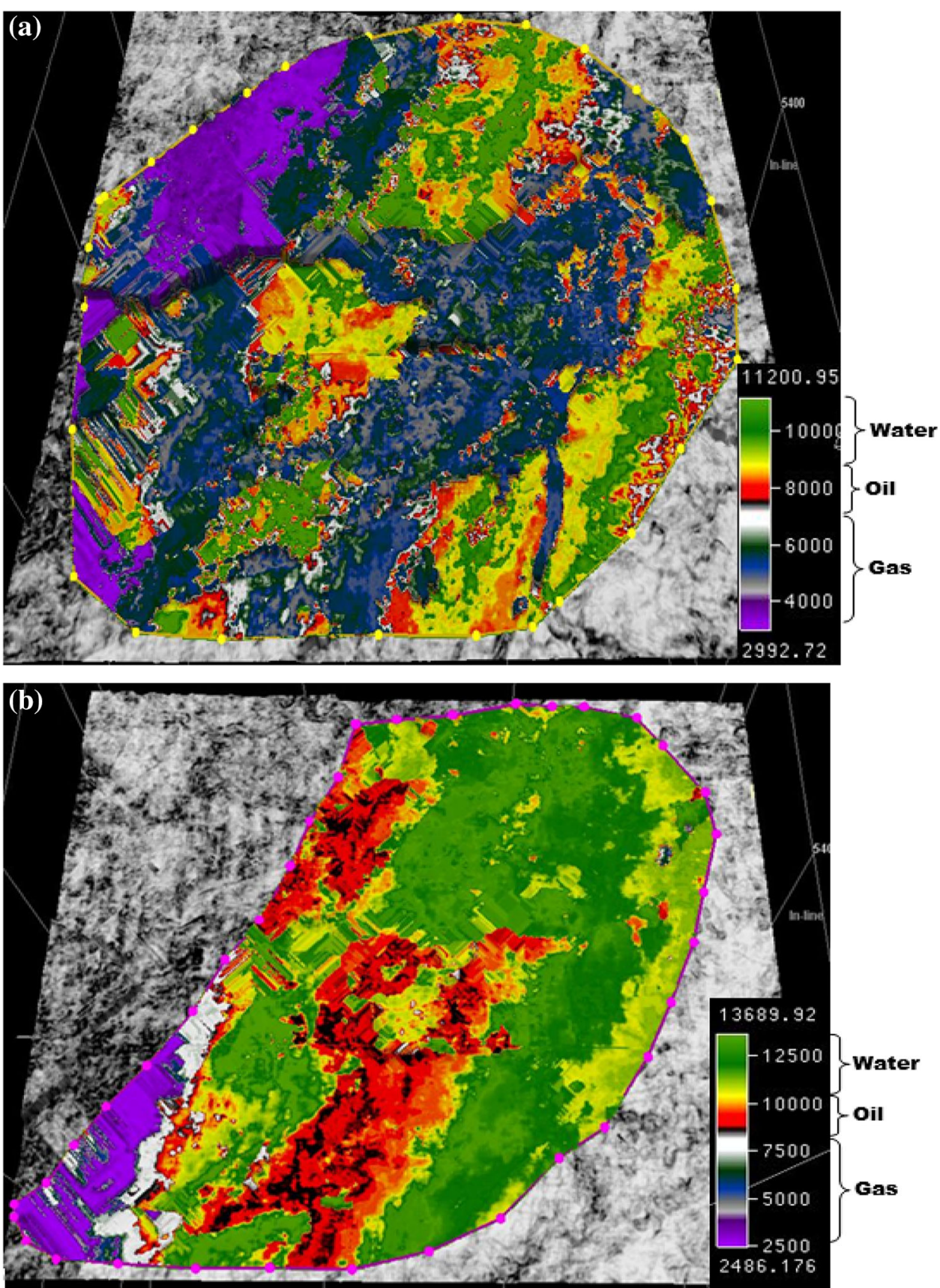

87.98 to $96.90 \%$ (well 0111), 80.70-92.80\% (well 0555). Based on the estimated porosity and permeability values, the reservoirs sand units have good potential for hydrocarbon exploitation. The porosity values range from 26.3 to $30.62 \%$ (well 0111), 21.30-28.30\% (well 0555), while the permeability values for both wells 0111 and 0555 range $2520.06-11,821.19 \mathrm{mD}$, and $1178.48-7764.42 \mathrm{mD}$, respectively.

II. The estimation of the above-mentioned petrophysical parameters did not consider structural uncertainties that are based on definition of both fluid contacts and fault plane. These uncertainties could result in ambiguity that can either overestimate or underestimate both gross rock volume (GRV) and volume of hydrocarbon in place.

III. Seismically derived chimneys were successful in highlighting hydrocarbon migration pathways. The delineated upwardly migration of hydrocarbon pool in the study area localized closer to the surface. The mapped faults seem to have lost their integrity; it appears the faults are non-sealing as evident from the 


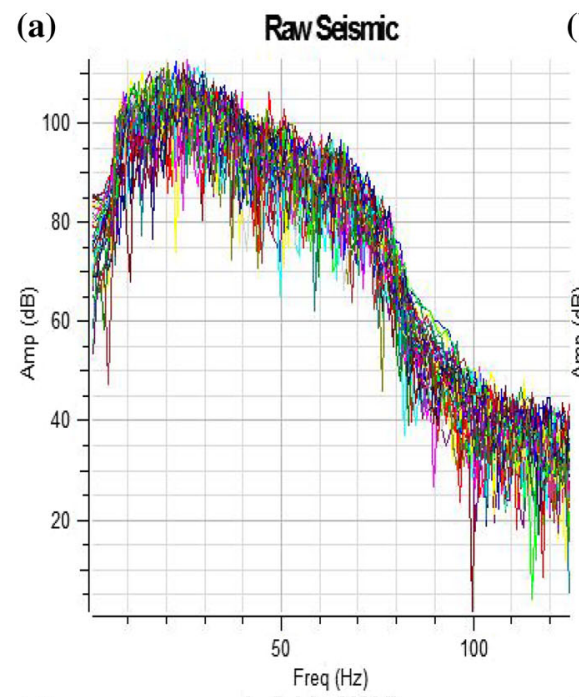

(d)

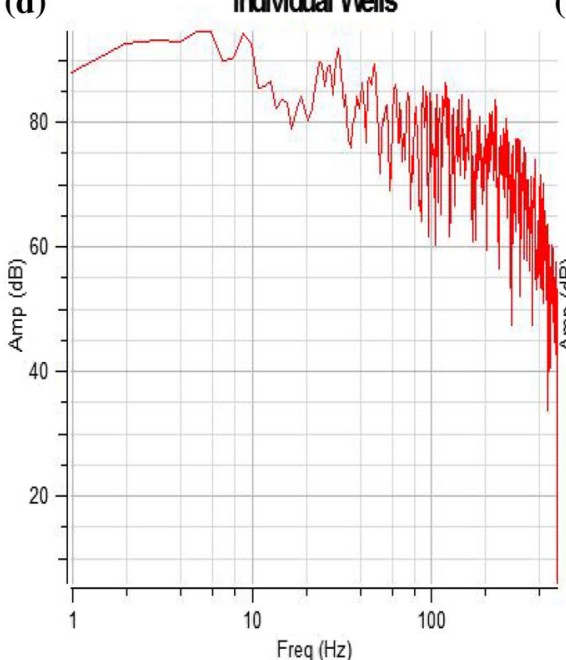

(b)

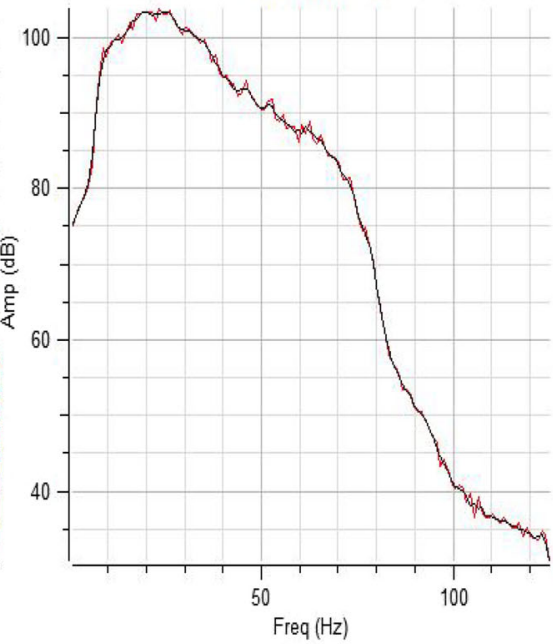

(e)

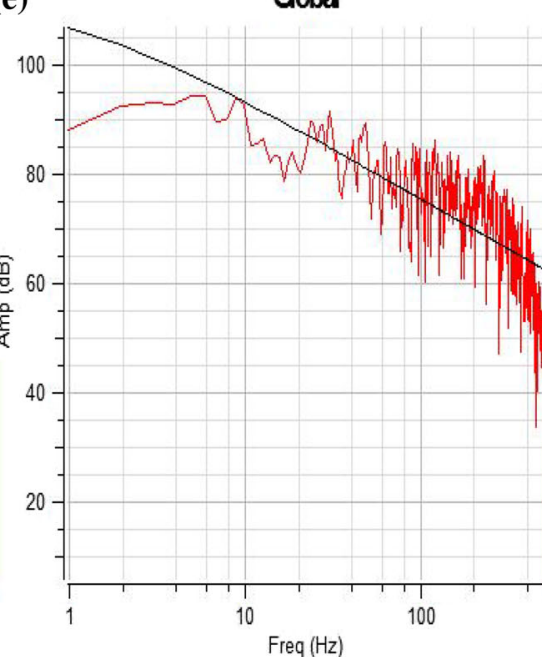

(c)

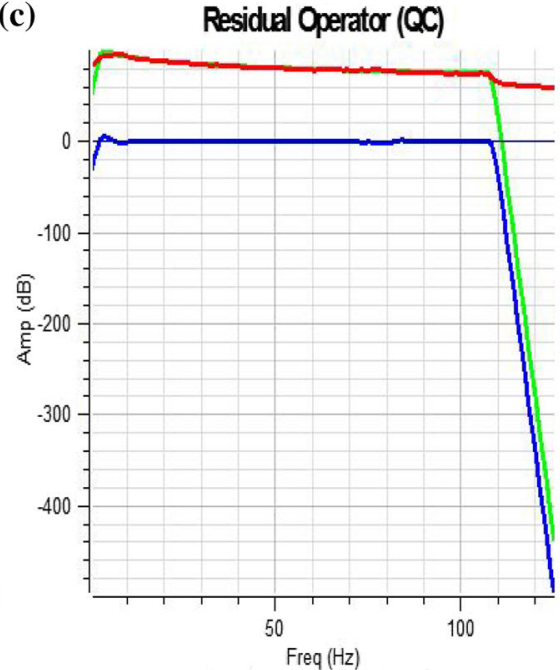

(f)

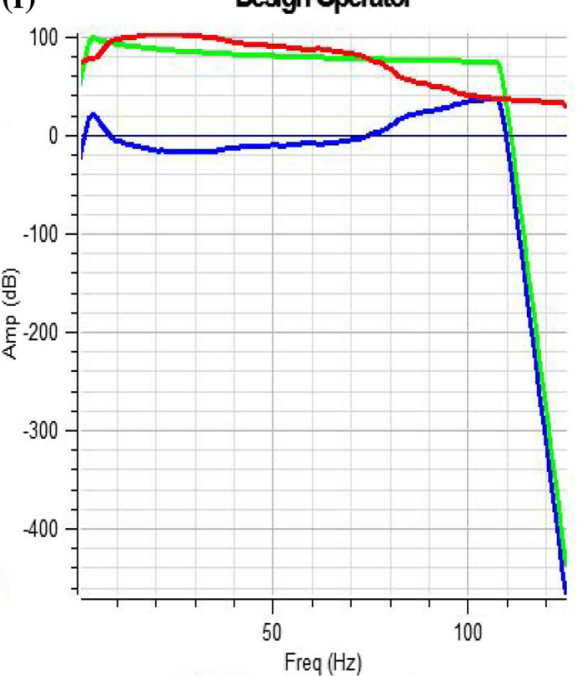

Fig. 15 Parameters used for generating seismic coloured inversion (SCI) (a) Raw seismic spectra, b smoothed version of the computed seismic mean amplitude spectra, $\mathbf{c}$ residual operator, $\mathbf{d}$ extracted wells impedance spectra, e global, this represents the computed mean of the

chimney analysis. It is recommended that proposed wells in this field should be within 600-1000 ms.

IV. Common contour binning (CCB) attributes revealed that the reservoir sand unit $\mathrm{R} 1$ in is more of gas filled, whereas R2 is oil filled. Both GOC and OWC contacts were delineated and mapped across the reservoir sand units.

V. Application of seismic coloured inversion on the seismic volume has revealed the reflectors and reservoir units sharper and clearer for further analysis wells impedance spectra and the curve fit line, $\mathbf{f}$ design operator, this was created by subtracting both mean amplitude spectra, rotating the phase spectrum by $-90^{\circ}$ and applying a bandpass filter

and qualitative interpretations. Subtle features were better defined on the seismic sections for mapping.

\section{Recommendations}

Provisions of core data and biostratigraphic data are necessary in this field for further research. It is important to validate the estimated petrophysical parameters using the 
Fig. 16 Seismic coloured inversion on inline 5364

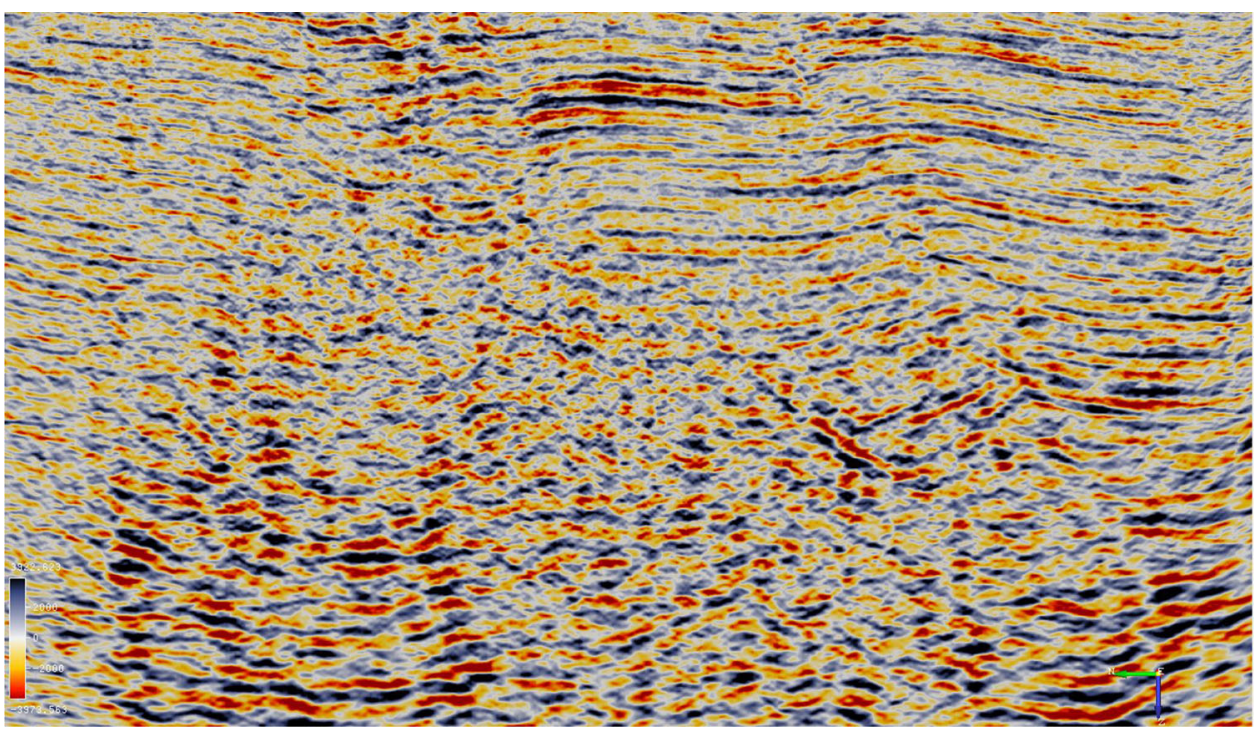

core data. There is need to carry out a high-resolution sequence stratigraphy in the field using the biostratigraphic data. This will provide the stratigraphic framework of the reservoir zonation with a view to assess the reservoir depositional architecture and to evaluate the reservoir quality.

Acknowledgements The authors wish to express their appreciations to the two reviewers and the editor for their efforts and their valuable comments that have improved this paper. We are grateful to dGB Earth Sciences and Schlumberger for providing the required software packages for this research. A lot of thanks due to Covenant University center for research innovation and development (CUCRID) for sponsoring this research. Also, deep thanks to the Nigerian department of petroleum resources (DPR) for providing us with the data.

Open Access This article is distributed under the terms of the Creative Commons Attribution 4.0 International License (http:// creativecommons.org/licenses/by/4.0/), which permits unrestricted use, distribution, and reproduction in any medium, provided you give appropriate credit to the original author(s) and the source, provide a link to the Creative Commons license, and indicate if changes were made.

\section{References}

Adeoye TO, Enikanselu PA (2009) Hydrocarbon reservoir mapping and volumetric analysis using seismic and borehole data over "Extreme" field, Southwestern Niger Delta Ozean. J Appl Sci 2(4):429-441

Al-Baldawi BA (2014) Petrophysical evaluation study of Khasib formation in amara oil field, South Eastern Iraq. Arab J Geosci. doi:10.1007/s12517-014-1371-5

Aminzade F, Connolly D (2002) Looking for gas chimneys and faults. AAPG Explor 23:20-21

Asquith G, Krygowski D (2004) Basic well log analysis. AAPG Methods Explor Ser 16:12-135
Bilotti F, Shaw JH (2005) Deep-water Niger Delta fold and thrust belt modeled as a critical- taper wedge: the influence of elevated basal fluid pressure on structural styles. AAPG Bull 89(11):1475-1491

BP (2014) Statistical review of world energy. www.bp.com/ statisticalreview

Briggs SE, Davies RJ, Cartwright J, Morgan R (2006) Multiple detachment levels and their control on fold styles in the compressional domain of the deepwater west Niger Delta. Basin Res 18:435-450

Caotes G, Denoo S (1981) The producibility answer product. Tech Rev Schlumbeger Huston 29(2):55-63

Cohen HA, McClay K (1996) Sedimentation and shale tectonics of the northwestern Niger Delta front. Mar Pet Geol 13(3):313-328

Connolly D, Aminzade F, de Groot P, Litenberg JH, Sawyer R (2002) Gas chimney processing as a new exploration tool: a West African example. In: Proceeding of AAPG annual meeting, pp 10-13

Connolly D, Aminzadeh F, Brouwer F, Nielsen S (2013) Detection of subsurface hydrocarbon seepage in seismic data: implications for charge, seal, overpressure, and gas-hydrate assessment. In: Aminzadeh F, Berge T, Connolly D (eds) Hydrocarbon seepage: from source to surface. SEG AAPG geophysical developments 16:199-220

Corredor F, Shaw JH, Bilotti F (2005) Structural styles in the deepwater fold and thrust belts of the Niger delta. AAPG Bull $89: 753-780$

Damuth JE (1994) Neogene gravity tectonics and depositional processes on the deep Niger delta continental margin. Mar Pet Geol 11(3):320-346

dGB (1995) Creating a good steering cube, dGB earth sciences. http:// static.opendtect.org/images/PDF/ effectivedipsteeringworkflowusingbgsteering_primerodata.pdf

dGB (2008) Common contour binning, www.dgbes.com/index.php/ newsletter.html

Doust H, Omatsola EM (1990) Niger Delta. In: Edwards, Santogrossi (eds) Divergent/passive margin basins. AAPG Mem 48:201-238

Ekweozor CM, Daukoru EM (1984) Petroleum source-bed evaluation of the tertiary Niger Delta reply. AAPG Bull 68:390-394

Evamy BD, Haremboure J, Kamerling P, Knaap WA, Molloy FA, Rowlands PH (1978) Hydrocarbon habitat of tertiary Niger Delta. AAPG Bull 62:277-298 
Ferguson RJ, Margrave GF (1996) A simple algorithm for bandlimited impedance inversion. CREWES Res 8(21):1-10

Heggland R (2004) Using gas chimneys in seal integrity: a discussion based on case histories. In: Boult P, Kardi J (eds) Evaluating fault and caprock seals. AAPG Hedberg series, pp 237-245

Heggland R, Meldahl P, Brill B, de Groot P (1999) The chimney cube, an example of semi-automated detection of seismic objects by directive attributes and neural networks: part 2 . Interpretation. In: 69th Annual international meeting, SEG Expanded Abstracts, pp. $935-940$

Kulke H (1995) Nigeria. In: Kulke H (ed) Regional petroleum geology of the world. Part II: Africa, America, Australia and Antarctica: Berlin, Gebruder Borntraeger, pp 143-172

Lancaster S, Whitcombe D (2000) Fast track coloured inversion. Expanded abstract, 70th SEG annual meeting, Calgary, pp 1572-1575

Larinov VV (1969) Borehole radiometry: Moscow, U.S.S.R. Nedra

Levorsen AI (1967) Geology of petroleum, 2nd edn. W.H Freeman and Co, San Francisco

Ligtenberg JH (2005) Detection of fluid migration pathways in seismic data: implications for fault seal analysis. Basin Res 17:141-153

Ligtenberg JH, Thomsen RO (2003) Fluid migration path detection and its applications for fault seal analysis. Basin Res 17:14-153

Meldahl P, Heggland R, Brill B, de Groot P (1999) The chimney cube, an example of semi-automated detection of seismic objects by directive attributes and neural networks: part 1. In: Methodology 69th annual international meeting, SEG, expanded abstracts, pp 931-934

Meldahl P, Heggland R, Brill B, de Groot P (2001) Identifying faults and gas chimneys using multi-attributes and neural networks. Lead Edge 20:474-482

Mode AW, Anyiam OA, Aghara IK (2014) Identification and petrophysical evaluation of thinly bedded low-resistivity pay reservoir in the Niger Delta. Arab J Geosci. doi:10.1007/s12517014-1348-4

Morgan R (2004) Structural controls on the positioning of submarine channels on the lower slopes of the Niger Delta. In: Davies RJ et al. (eds). 3D Seismic technology: applications to the exploration of sedimentary basins. Geol Soc Spec Mem, pp 45-51
Morris RL, Briggs WP (1967) Using log-derived values of water saturation and porosity, Trans. SPWLA annual logging symposium paper, pp 10-26

Opara AI (2010) Prospectivity evaluation of "Usso Field", onshore Niger Delta basin using 3-D seismic and well log data. Petrol Coal 52(4):307-315

OPEC (2016) Annual statistical bulletin. www.opec.org/opec_web/ en/publications/202.htm

Reijers TJA (2011) Stratigraphy and sedimentology of the Niger Delta. Geologos 17(3):133-162

Schlumberger (1989) Log interpretation, principles and application, schlumberger wireline and testing, Houston. Texas, pp 21-89

Shepherd M (2009) Where hydrocarbons can be left behind, in oil field production geology. AAPG Mem 91:211-215

Sutrisno WT, Prahastudhi S, Bahri AS, Wulandari YP (2013) Application of common contour binning (CCB) and back propagation neural network for oil water contact prediction in carbonate reservoir. In: Proceeding of Indonesian petroleum association 37th annual convention and exhibition

Swissi A, Morozov IB (2009) Impedance of blackfoot 3D seismic dataset CSPG/CSEG/CWLS Geoconvention 2009 Calgary Alberta Canada

Tingdahl KM (2003) Improving seismic chimney detection using directional attributes. In: Nikravesh M, Aminzadeh F, Zadeh LA (eds) Soft computing and intelligent data analysis in oil exploration. Dev Petrol Sci 51:157-173

Veeken PCH, Da Silva M (2004) Seismic inversion methods and some of their constraints. First Break 22:48-70

Wyllie MRJ, Gregory AR, Gardner LW (1956) Elastic wave velocities in heterogeneous and porours media. Geophysics 21(1):41-70. doi:10.1190/11438217

Zhao Z, Yang R, Ma Y (2013) Method for pinpointing the contacts of oil, gas and water by common contour binning stacking and its application. Nat Gas Geosci 24(4):808-814

\section{Publisher's Note}

Springer Nature remains neutral with regard to jurisdictional claims in published maps and institutional affiliations. 